\title{
Combining habitat and biological characterization: Ecological validation of the river habitat survey
}

\author{
Rui Manuel Vitor Cortes ${ }^{1, *}$, Simone Varandas de Oliveira ${ }^{1}$, Samantha Jane Hughes ${ }^{2}$ and \\ Maria Teresa Ferreira ${ }^{3}$ \\ ${ }^{1}$ Depart. Florestal, Universidade de Trás-os-Montes e Alto Douro, 5001-801Vila Real, Apartado 1013, Portugal. \\ Tel: 351259350862. \\ ${ }^{2}$ Centre for Macaronesian Studies, University of Madeira, Campus da Penteada, Funchal 900-390, Portugal. \\ ${ }^{3}$ Depart. Engenharia Florestal, Instituto Superior de Agronomia, Tapada da Ajuda, 1349-017 Lisboa, Portugal.
}

* Corresponding author: rcortes@utad.pt

Received: 13/07/07

Accepted: 12/11/07

\begin{abstract}
Combining habitat and biological characterization: ecological validation of the river habitat survey

The River Habitat Survey (RHS) is a widespread technique used to characterize the habitats at the fluvial sector level and to quantify the magnitude of physical disturbances. In this study we tested the ability of this method to discriminate sites along a gradient of perturbation and to analyse its relation with typological and environmental features.

At the same time, a biological validation of RHS parameters was carried out by crossing the descriptors with three different aquatic communities (benthic macroinvertebrates, fish, and macrophytes). The Portuguese sector of the Douro basin was the area selected for this purposes.

Ordination and classification techniques were used to achieve the objectives mentioned, after a reduction of the variables as a function of their relationships and according to their affinity. The multivariate analysis revealed that the variables associated with the river corridor were more appropriate to differentiate the sampling stations along the gradient of disturbance.

However, these variables, together with the ones describing the river conditions (together with the RHS derived indices) were strongly dependent on the typological characteristics.

This work shows an adequate strategy for the characterization of the fluvial habitat with biological data to obtain an integrated ecological vision.
\end{abstract}

Key words: RHS, biological characterization, physical characteristics, integrated ecological assessment.

\section{RESUMEN}

\section{Combinando hábitat y caracterización biológica: validación ecológica del "river habitat survey"}

El River habitat Survey (RHS) es una técnica ampliamente utilizada para caracterizar el hábitat a nivel de sector fluvial y para cuantificar la magnitud de las perturbaciones físicas. En este estudio probamos la habilidad de este método para discriminar puntos a lo largo de un gradiente de perturbación y analizar su relación con las características tipológicas y ambientales. Al mismo tiempo, se realiza una validación biologica de los parámetros RHS, cruzando los descriptores con tres comunidades acuáticas diferentes (macroinvertebrados bénticos, peces y macrófitos). El sector portugués de la cuenca del Duero fue el área seleccionada para nuestros propósitos.

Se utilizaran técnicas de ordenación y clasificación para lograr los objetivos mencionados, después de realizar una reducción de variables en función de sus relaciones atendiendo a su afinidad. El análisis multivariante reveló que las variables asociadas con el corredor ripário fueran más apropiadas para diferenciar puntos de muestreo a lo largo del gradiente de perturbación. Sin embargo, estas variables conjuntamente con las que describen las condiciones del río (conjuntamente con los índices derivados del RHS) fuero altamente dependientes de las características tipológicas.

Este trabajo pone en evidencia una estrategia adecuada para la caracterización del hábitat fluvial con datos biológicos para obtener una visión ecológica integral.

Palabras clave: RHS, caracterización biológica, características físicas, evaluación ecológica integrada. 


\section{INTRODUCTION}

The development of bioassessment methods combined with the advances in geographic information systems and spatial analysis in landscape ecology has resulted in a growing research interest on the influence of land use on habitat disturbance at different spatial scales as well as its impact on aquatic communities. In comparison with water quality studies (biological or chemical characterization), physical habitat evaluation is a relatively young discipline that needs to be better developed in order to be adopted for profitable river management (Maddock, 1999; NRA, 1996). Initially, management aims focused on economic and safety needs, with river improvement aimed towards the protection of urban areas from floods, adequate drainage of agricultural areas, waterpower, and works for navigation purposes.

However, the importance of morphological and structural features of the riverbed and the riparian zone in ecological monitoring has demanded increasingly more attention worldwide. This is the case of Austria and Germany, where the results of extensive surveys have been published as maps (see Muhar et al., 2004, and Kamp et al., 2004 for historic revisions and specific applications of the habitat assessment methods used in these countries, where LAWA is extensively used). Physical monitoring, initially restricted to specific mesohabitats, has been expanded to basin level in order to include the entire river and flood plain system (Binder \& Kraier, 1999). In the UK, habitat assessment has been successively improved with important tools such as the River Corridor Survey (NRA, 1992) and River Habitat Survey or RHS (Raven et al., 1997). The latter method, a recognized reach-scale assessment technique, has been successfully used to assess the whole geomorphological variation of Great Britain and Ireland. RHS has also been constantly modified to incorporate urban or heavily engineered rivers, like the Urban River Survey or URS (Davenport et al., 2004), or for assessments in Mediterranean rivers (Buffagni, 2004). In France, the SEQ-MP is probably the major technique for river conservation status assessment and has been widely applied across the national territory.

In the USA, extensive habitat surveys are conducted by several organizations such as the Environmental Protection Agency, the Forest Services, and the Bureau of Land Management. Several evaluation systems have been produced: a recent example is the Non-Wadeable Habitat Index (NWHI, Wilhelm et al., 2005). In Australia, River Styles (Brierley \& Fryirs, 2000 ) is a generic geomorphological framework applied to coastal river systems that uses four interrelated scales. This assessment procedure requires evolutionary knowledge specific to each river type, adjustment capacity and the natural range of variability (Fryirs, 2003).

Although a substantial number of habitat assessment procedures have been developed, they are only meaningful if the physical features assessed have biological significance. Unfortunately, the successful integration of habitat and biological descriptors is relatively rare. Thompson et al. (2001) suggest that these barriers may be created as a consequence of different spatial scales being relevant to different biota and that assessment procedures ideally should provide information on processes that degrade habitat at each of these spatial scales. An exception to the aforementioned lack of interaction between habitat and aquatic life is SERCON, a conservation-oriented programme combining chemical, physical and biological information (Boon et al., 1997).

Setting ecological status targets according to the Water Framework Directive (WFD), which adopts the concept that the analysis of hydromorphological elements should complement the high status of biological assessment, requires a well developed understanding of the links between the environmental condition and the biota (Logan \& Furse, 2002). Moreover, the definition of reference conditions requires, besides pressure check analyses, an appropriate characterisation of the hydromorphological elements (González del Tanago \& Garcia de Jalon, 2006).

The WFD Programme of Measures, which aims to raise impacted ecosystems to the level of "good" ecological status, requires the 
establishment of reliable links between habitat disturbance and biological elements in order to design and implement essential and appropriate remedial actions. However, as a consequence of the aforementioned difficulties, relationships between the biota and the environmental factors have been traditionally established for specific taxonomic groups and separate river habitat components. An example is the Physical Habitat Simulation (PHABSIM) used for defining the instream flow for target species (Stalkner, 1994). Although RIVPACS, the River InVertebrate Prediction And Classification System (Wright et al., 2000), provides a robust link between a selected group of habitat parameters and a specific community (benthic macroinvertebrate fauna), the assessment of the test sites lays exclusively on this assemblage (by comparing it to the assemblage occurring at reference sites with similar physical conditions).

A few approaches developed to procure the link between physical descriptors at various spatial scales and the biota, use the habitat to qualify the ecological status of running waters. Examples are the Index of Stream Condition (ISC - Ladson et al., 1998) which comprises an empirical set of environmental and biological indicators that can be easily understood by river managers, or the mesohabitat approach (Tickner et al., 2000), from which an index of instream habitat quality is derived using data on the distribution and characteristic fauna of medium scale habitats. The assumption is that management, conservation or rehabilitation of reaches and segments is more practical than management of individual species or stream communities. More recently, Oliveira \& Cortes (2005) developed the Habitat Condition Index (HCI), based on biologically relevant habitat parameters, which attempted to incorporate distinct spatial scales of analysis.

The objective of this study is to test the ability of RHS variables and indices to discriminate sites along gradients of anthropogenic perturbation and their relation to typological and environmental features. An independent biological validation of RHS parameters was then carried out on three different biological elements of the aquatic community (benthic macroinver- tebrates, fish and macrophytes). We have focused on the RHS technique since it has been applied over the Portuguese national territory to complement the characterization of biological elements under the implementation of the WFD. The entire Portuguese sector of the Douro basin was the geographical area selected for this purpose. Crossing the descriptors from the multiple RHS variables with the biological data had two objectives: a) to detect the most relevant physical features associated with the composition and structure of the aquatic communities; $b$ ) to assess at which spatial scale the biota is influenced by such habitat features. We also hope that this work may help to identify appropriate strategies for integrating habitat and biological surveys in two essential areas: data collection and integrate ecological assessment of biological and hydromorphological features.

\section{METHODS}

The entire stream network of the Douro basin in Portuguese land (Oliveira \& Cortes, 2005) was sampled in the spring of 2004 and 2005. A total of 83 sampling stations were considered, encompassing a complete range of environmental conditions. Such selection relied on the criteria set down by the European Project FAME, linked to the implementation of the WFD (Schmutz, 2004), which considers a set of 10 parameters to quantify the degree of the human pressures: 1) river connectivity, 2) land use, 3) urban area, 4) riparian zone, 5) sediment load, 6) hydrological regime, 7) impoundment, 8) morphological condition, 9) symptoms of acidification or toxicity and, 10) input of organic nutrientsclasses 1 to 5). Reference or minimally disturbed sites, assessed in the first year (42 sites), were scored with the impact class 1 and, highly disturbed ones, studied in the second year (41 sites), were scored with the impact class 4 or 5 . The aquatic communities were sampled using semiquantitative procedures in an area comprised in a reach of 50 metres in length, disturbing the riverbed to dislodge the benthic macroinvertebrate fauna. These organisms were obtained by 
the kick-sampling method from 6 transects $(1 \mathrm{~m}$ length by $0.25 \mathrm{~m}$ width) covering the different habitats, starting at a riffle. The instream habitats were sampled in proportion to its representation. Habitats sampled included aquatic macrophytes, organic matter, mud/silt, woody debris, coarse and sandy substrates and pools, channel, edge, sedimentation, and erosion zones. Each sample consisting of a composite of 6 transects, was collected with a hand-net $(0.50 \mathrm{~mm}$ mesh size) and was immediately sorted in the laboratory. Organisms were preserved in $70 \%$ ethanol and identified to family level.

Fishes were captured by electrofishing (backpack or by boat), operated in a single pass and following a CPUE approach (constant capture effort in each meso-habitat), but including all the habitats (total distance surveyed, 20 times the mean river width up to a maximum length of $150 \mathrm{~m}$ ). Stunned fishes were placed in containers to recover, identified to species, counted, and released. Abundance was expressed in number $/ \mathrm{m}^{2}$. Macrophytes were sampled by wading along a zigzag transect for $200 \mathrm{~m}$ of the river channel and banks. A careful search was made along the transect in order to score each taxa on a scale according to its coverage. When necessary, plant specimens were taken to the laboratory for subsequent identification.

Water quality data (oxygen, water temperature, conductivity, $\mathrm{pH}, \mathrm{COD}, \mathrm{BOD}$, alkalinity, hardness, TSS, $\mathrm{NO}_{3}^{-}, \mathrm{NO}_{2}^{-}, \mathrm{NH}_{4}^{+}, \mathrm{PO}_{4}^{3-}$, total $\mathrm{N}$, and total $\mathrm{P}$ ) was collected in each site and were further divided in 5 classes according to the criteria of the Portuguese Water Institute (INAG), which classifies water quality for different uses. Thus, a site was considered unimpaired if it belonged to class $\mathrm{A}$ and impaired if it belonged to classes D or E.

Habitats were assessed using RHS (Raven et al., 1997), a method that relies on the standardised collection of observational data over $500 \mathrm{~m}$ length of the river and its corridor extending $50 \mathrm{~m}$ outwards on either side. Observations are conducted at two different scales: (i) at perpendicular transects or "spot checks" every $50 \mathrm{~m}$ and (ii) continuously along whole the $500 \mathrm{~m}$ survey site ("sweep up").
At each of the 10 spot-checks surveys of channel substrate, flow type, habitat features, aquatic vegetation types, bank vegetation structure and artificial modifications are made. Sweep-up ensures that physical features and modifications occurring outside the spot-checks are recorded. Additional information is recorded related to target taxa and morphometric measurements and are made at a representative cross section of the survey site. RHS has two scoring systems: one to compare habitat quality (HQA), resulting from the sum of 10 sub-indices (expressing the physical habitat diversity, vegetation cover, hydrodynamic characteristics of the river channel, and the use of adjacent marginal land). The Habitat Modification Score (HMS) quantifies the extent of human intervention (e.g. weirs, bank protection, water diversion, and extraction along the channel. Developed primarily for use in England and Wales, comparisons should be made between the same river types, defined by similar attributes related to altitude, geology and size (by comparing the position of the test site with reference sites through a principal components analysis). The RHS method, because uses a great variety and disparity of variables, is a usefulness process given that embraces descriptors of riverine and fluvial habitats. Thus, it acts as an important work base in terms of field evaluation of most of the indispensable hydromorphological parameters. However, one of the main handicaps consists in the fact of the component associated with the hydrological alterations, an indispensable requirement of WFD, do not contemplate the generality of the items contained in this document.

All the field studies (biological collections, chemical parameters and observation of habitat descriptors) took place at the same time in each site. During the first year of this study collections were made under abnormally low flow conditions (a 60 year record of minimum rainfall).

In order to facilitate multivariate data treatment, RHS variables were primarily grouped according to the features described in Appendix 1. By grouping and creating new variables the number of zeros in the data set as well as the number of parameters in the original larger set of habitat parameters was reduced. The new variables 
were divided into one of two classes: a) descriptors of in-stream conditions; b) descriptors of the river corridor. These variables were not divided in classes, but the scores were standardized for statistical analyses.

Multiple Discriminant Analysis (MDA) was used to ordinate the original RHS variables according to basin or typological physical descriptors, namely tributary catchment area, altitude, slope, distance to source, run off and land cover use, as well as anthropogenic descriptors used by FAME (Schmutz, 2004). Table 1 lists the environmental variables used to test RHS. Typological and disturbance variables were allocated in 5 classes.

Non Metric Multidimensional Scaling (MDS) was used to assess the ability of the RHS (grouped) variables to separate sites along the disturbance gradients. MDS considers the rank order of distances between objects, obtained from the Jaccard coefficient of similarity. Canonical Correspondence Analysis (CCA) was then used to extract the main RHS variables associated to each set of biotic data (invertebrates, fishes, and macrophytes); this direct gradient analysis technique simultaneously uses both sets of data (biotic and abiotic variables) to select the linear combination of environmental parameters that maximize the dispersion of species scores obtained in a separated ordination. Macroinvertebrate data was previously transformed by $\log (x+1)$ and families with less than 2 pres- ences in each sample of the data set were excluded. Finally, a Canonical Analysis (CA) was carried out in order to assess the dependence of the RHS (grouped) variables, the HQA subindices and the HMS index from the 3 sets of environmental descriptors presented in Table 1; this method interacts between two distinct matrices with the aim of computing the proportion of variance shared by the sum of scores (canonical variates) in each set. Multivariate analyses were performed using the software packages STATISTICA 7.0 (Statsoft, 2004) and CANOCO 4.5 (ter Braak \& Smilauer, 2002).

\section{RESULTS}

Box-plot graphics of HQA and HMS indices (Fig. 1) reveal the strong limitations of these indices in separating reference sites from disturbed sites. Even though the final HQA index value may appear to discriminate between these two groups, detailed analysis of the sub-indices reveal that only HQA trees and HQA bank vegetation are sensitive to human impacts, meaning that remaining HQA variables are not relevant for this purpose. Site separation based on the HMS index is also poor, since habitat change in the Douro basin is very often not a strict consequence of the presence of artificial structures on the river banks and in the channel but of general habitat impoverishment related to extensive agriculture.

Table 1. Environmental variables used to test RHS according to typological and disturbance gradients. Soil use was obtained by GIS and local stress factors were observed in situ by experts of the area surrounding the sampling station. Variables ambientales usadas para testar el RHS de acuerdo con los gradientes tipológicos y de perturbación. El uso del suelo fue obtenido por GIS y los factores de stress locales fueran observados in situ por expertos en el área alrededor del sitio de muestreo.

\footnotetext{
Tipology and climate

Altitude; Mean yearly runoff; Catchment area; Distance from source; Slope; Mean yearly precipitation; Mean yearly air temperature.

Soil use in the catchment $(\%)$

Intensive agriculture; Extensive agriculture; Natural areas; Urban areas.

Local Stressors (FAME variables expressed in classes)

Soil use; Urban area; Structure of riparian layer; River connectivity; Sediment load; Hydrological modifications; Symptoms of acidification or toxicity; Morphological condition; Symptoms of eutrophication; Impoundments.

Water Quality

Water temperature; Dissolved oxygen (mg/L and \%)); $\mathrm{pH}$; Conductivity; Biochemical oxygen demand; Chemical oxygen demand; Alkalinity; Hardness; Total suspended solids; $\mathrm{NO}_{3}^{-} ; \mathrm{NO}_{2}^{-} ; \mathrm{NH}_{4}^{+}$; Total N; Total $\mathrm{P} ; \mathrm{PO}_{4}^{3-}$.
} 

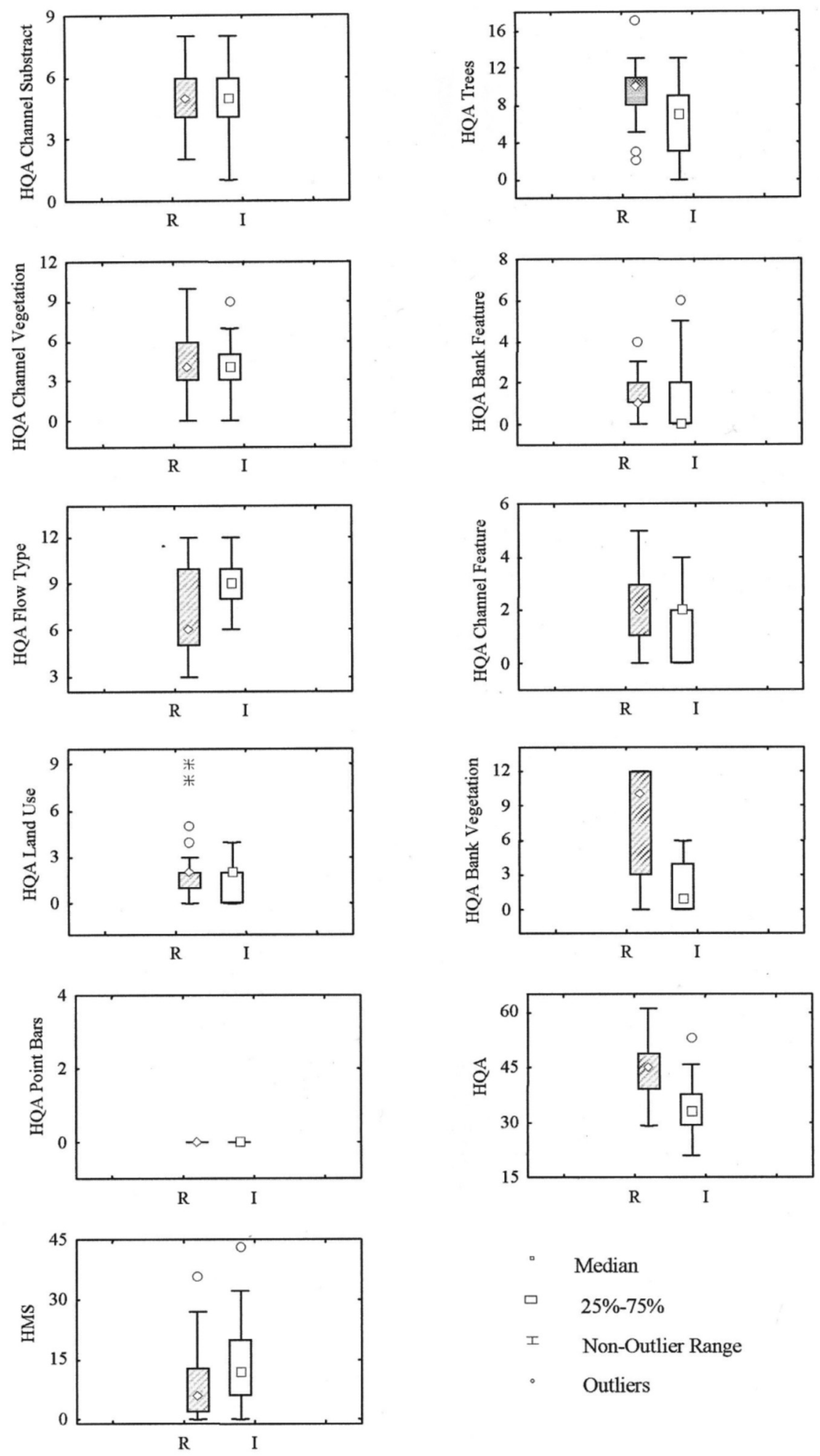

Figure 1. Box-plots of the total and partial HQA and HMS indices. Box-plots del HQA total y parcial e índices del HMS. 
Table 2. MDA results obtained separately for the matrix of the RHS descriptors and the matrix of RHS indices (partial HQA and HMS indices). Resultados de MDA obtenidos separadamente para la matriz de los descriptores del RHS y la matriz de índices de RHS (HQA parcial e índices de HMS).

\begin{tabular}{|c|c|c|c|c|}
\hline \multicolumn{5}{|l|}{ RHS VARIABLES } \\
\hline discriminant variable & variables in the model & Wilks' Lambda & $\mathbf{F}$ & $\mathbf{p}$ \\
\hline Catchment area & 23 & 0.06427 & 3.7356 & 0.0000 \\
\hline Altitude & 35 & 0.00412 & 3.7770 & 0.0000 \\
\hline Slope & 22 & 0.11403 & 1.8947 & 0.0001 \\
\hline Distance from source & 31 & 0.00978 & 3.4359 & 0.0000 \\
\hline Runoff & 33 & 0.01744 & 2.4849 & 0.0000 \\
\hline Natural areas & 49 & 0.00044 & 3.7017 & 0.0000 \\
\hline \multicolumn{5}{|l|}{ RHS INDICES } \\
\hline Discriminant variable & Variables in the model & Wilks' Lambda & $\mathbf{F}$ & $\mathbf{p}$ \\
\hline Catchment area & 6 & 0.49557 & 2.3767 & 0.0005 \\
\hline Altitude & 9 & 0.46101 & 2.3389 & 0.0004 \\
\hline Slope & 2 & 0.81363 & 2.0912 & 0.0398 \\
\hline Distance from source & 7 & 0.46455 & 2.2088 & 0.0007 \\
\hline Runoff & 4 & 0.69278 & 1.8332 & 0.0281 \\
\hline Natural areas & 5 & 0.30910 & 5.2325 & 0.0000 \\
\hline
\end{tabular}

In order to assess the extent of RHS dependence on the natural longitudinal gradients associated with the transition from upland to lowland areas, two MDA analyses were performed: a) one using the RHS variables (grouped); b) the other from the matrix with the various RHS indices (HQA sub-indices and the HMS index). Classed into 5 groups, the discriminant variables used were catchment area, altitude, slope, distance to the source, run-off, and proportion of natural

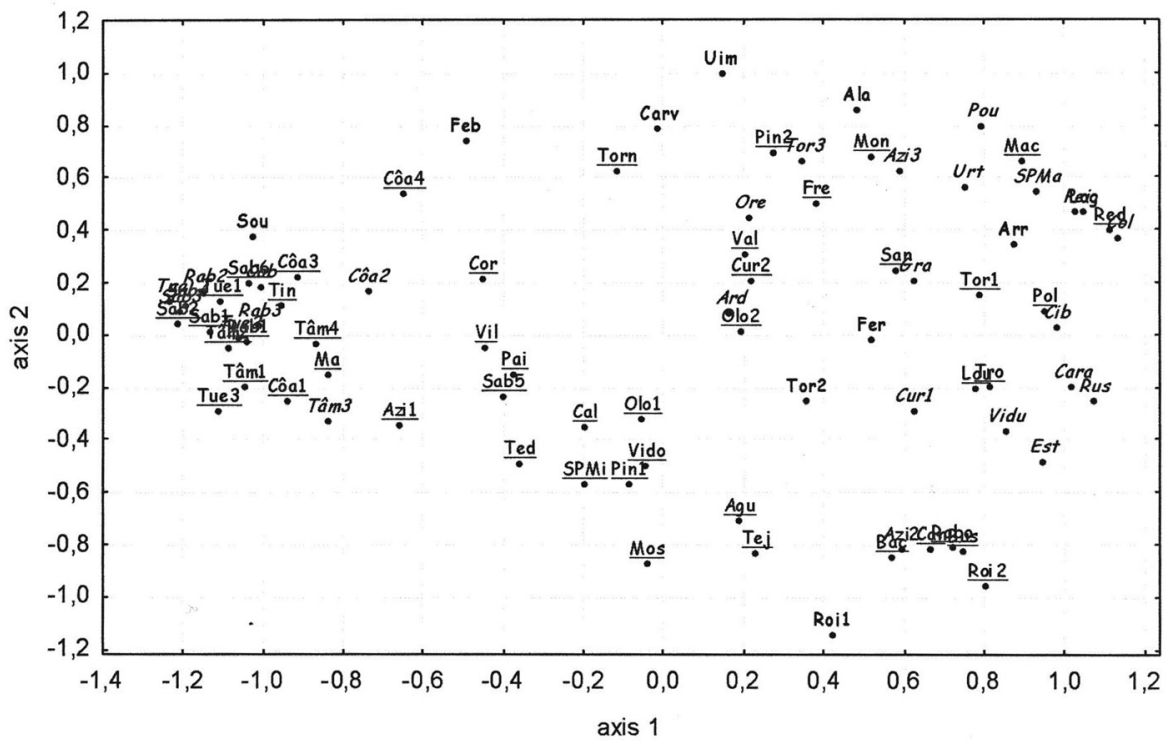

Figure 2. MDS analysis of the matrix of transformed RHS variables related to the river characteristics. Sites are assigned according to the level of disturbance: the underlined ones represent the reference situation; the ones in italic indicate the intermediate disturbance and the other ones (without any special mark) correspond to the most impacted sites. Análisis MDS de la matriz de variables RHS transformadas relacionadas con las características del río. Los sitios son asignados según el nivel de perturbación: los subrayados representan la situación de referencia; en cursiva los que presentan perturbación intermedia y los restantes (sin cualquier marca especial), corresponden a las sitios más impactados. 


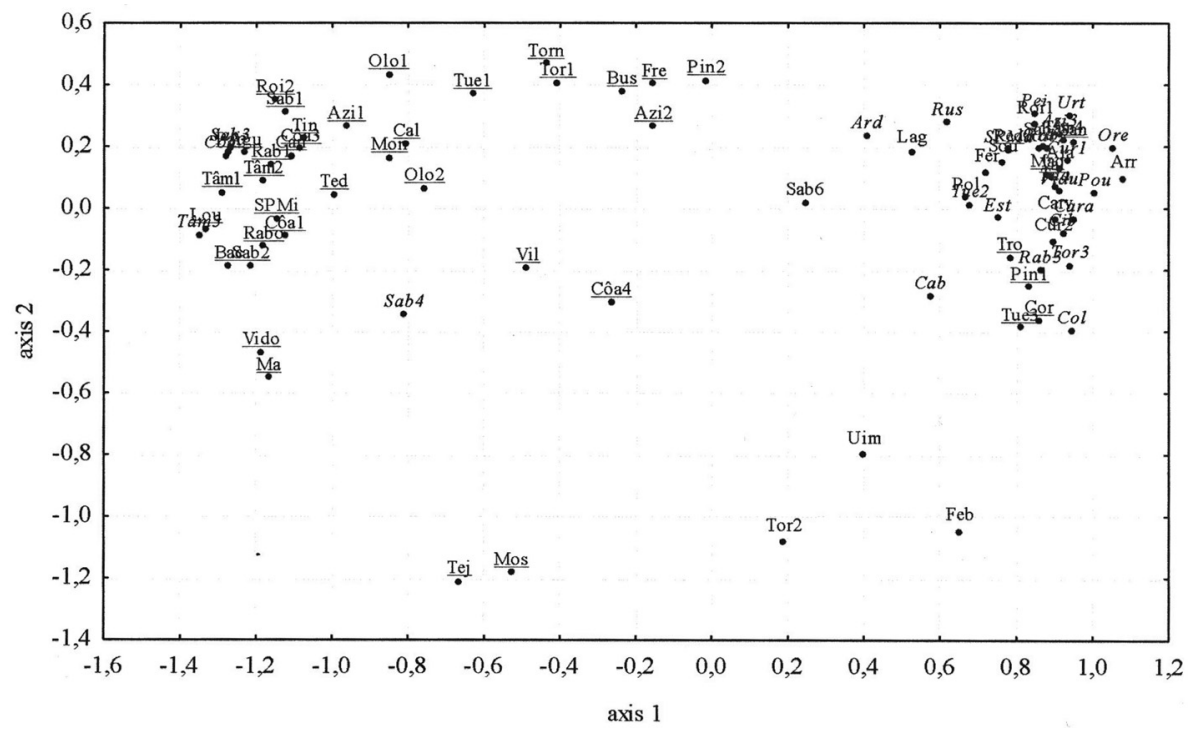

Figure 3. MDS analysis of the matrix of transformed RHS variables related to the river corridor. Sites are assigned according to the level of disturbance: the underlined ones represent the reference situation; the ones in italic indicate the intermediate disturbance and the other ones (without any special mark) correspond to the most impacted sites. In the diagram, it is apparent that most of the disturbed sites are located to the right, whereas the reference ones are grouped on the left side. Análisis MDS de la matriz de variables RHS transformadas relacionadas con el corredor fluvial. Los sitios son asignados según el nivel de perturbación: los subrayados representan la situación de referencia; en cursiva los que presentan perturbación intermedia y los restantes (sin cualquier marca especial), corresponden a los sitios más impactados. En el diagrama observamos como la mayoría de los sitios perturbados se localizan a la derecha, mientras que los de referencia se agrupan en el lado izquierdo.

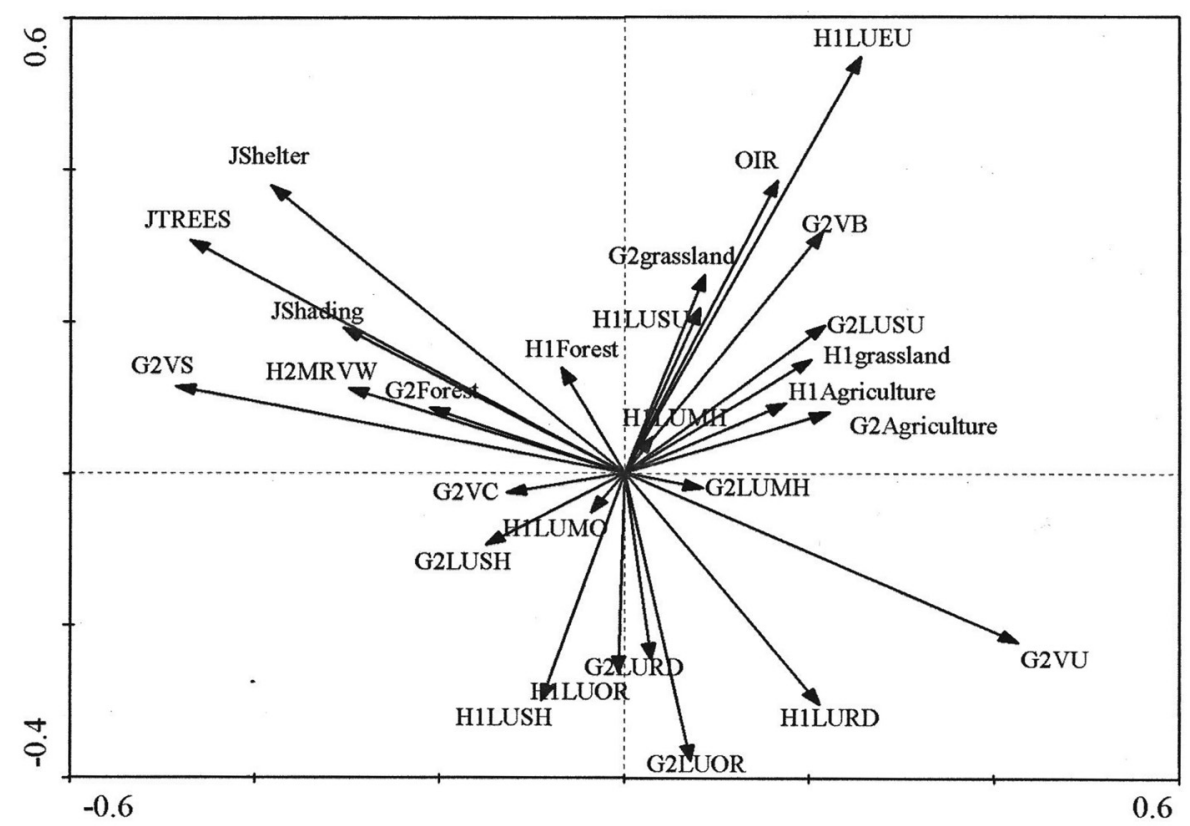

Figure 4. CCA analysis of RHS variables (grouped) of the river corridor and the abundance of invertebrate families. Only the environmental variables are represented. Análisis CCA de las variables RHS (agrupadas) del corredor fluvial y la abundancia de familias de invertebrados. Se representan simplemente las variables ambientales. 
Table 3. Results of the CCA analysis of the different communities. Resultados del análisis CCA de las diferentes comunidades.

\begin{tabular}{|c|c|c|}
\hline COMMUNITY & $\mathrm{X1}$ & $\mathbf{X 2}$ \\
\hline Invertebrates & $\begin{array}{l}\text { Eigenvalue: } 0.1329 \\
\text { Corr sp./amb: } 0.8209 \\
\text { FR explained }>2.1 \\
\text { JTREES } \\
\text { H1LUEU } \\
\text { G2LURD } \\
\text { G2VB } \\
\text { H1LURD } \\
\text { G2VU } \\
\text { H1LUSU } \\
\text { G2Grassland } \\
\text { H1LUOR } \\
\text { HIForest }\end{array}$ & $\begin{array}{l}\text { Eigenvalue: } 0.1003 \\
\text { Corr sp./amb: } 0.7843 \\
\text { FR explained }>2.1 \\
\text { H1LUSH }\end{array}$ \\
\hline Fishes & $\begin{array}{l}\text { Eigenvalue: } 0.5353 \\
\text { Corr sp./amb: } 0.9562 \\
\text { FR explained }>2.1 \\
\text { H1LUEU } \\
\text { H1LURD } \\
\text { H1LUSU } \\
\text { G2VB } \\
\text { H1LUOR }\end{array}$ & $\begin{array}{l}\text { Eigenvalue: } 0.3330 \\
\text { Corr sp./amb: } 0.8172 \\
\text { FR explained }>2.1 \\
\text { H1Grassland }\end{array}$ \\
\hline Macrophytes & $\begin{array}{l}\text { Eigenvalue: } 0.7312 \\
\text { Corr sp./amb: } 0.9475 \\
\text { FR explained }>2.1 \\
\text { JShelter } \\
\text { H1LUSH } \\
\text { H1LURD } \\
\text { G2VS } \\
\text { G2VU } \\
\text { H1LUOR } \\
\text { H1LUEU }\end{array}$ & $\begin{array}{l}\text { Eigenvalue: } 0.6672 \\
\text { Corr sp./amb: } 0.9356 \\
\text { FR explained }>2.1 \\
\text { G2LURD } \\
\text { H1LURD } \\
\text { G2LUOR } \\
\text { G2Forest } \\
\text { G2LUSH } \\
\text { G2Grassland }\end{array}$ \\
\hline
\end{tabular}

areas. Table 2 illustrates the clear dependence of the transformed RHS variables and the different indices on the typological descriptors.

Sites were ordinated using MDS using the matrix of RHS transformed variables but differentiating for instream variables and river corridor variables. Observation of the MDS plots (Figs. 2 and 3) reveal that variables associated with the river corridor effectively separate the sampling stations along a disturbance gradient, whereas the instream variables are practically ineffective for this purpose. The MDS stress values were both less than 0.20, which indicates an appropriate representation of the multidimensional distances (Clarke \& Warwick, 1999). Sites in the two figures are assigned to one of three classes according to the level of disturbance, based on 18 variables divided in 2 sets: 9 are FAME variables (connectivity was excluded) and 9 describe the water quality (oxygen, conductivity, COD, BOD, oxidability, TSS, $\mathrm{NO}_{3}^{-}, \mathrm{NH}_{4}^{+}$and $\mathrm{PO}_{4}^{3-}$ ). The results clearly show that only the variables describing river corridor were able to discriminate between disturbed and reference sites.

Further analyses were carried out on river corridor condition variables only which were crossed with the aquatic communities assemblage matrices through CCA analyses (Figs. 4-6 and Table 3). Environmental variables related to the structure of the riparian layer (JShelter, JTREES, JShading, and G2VS) are important determinants for macroinvertebrate assemblages (Fig. 4) as well as disturbance indicators such as the presence of exotic plant species (H1LUEU and OIR), low vegetation diversity, and urban development (G2VU and G2LUSU). Thus reference sites are plotted in the ordination space according to the aforemen- 


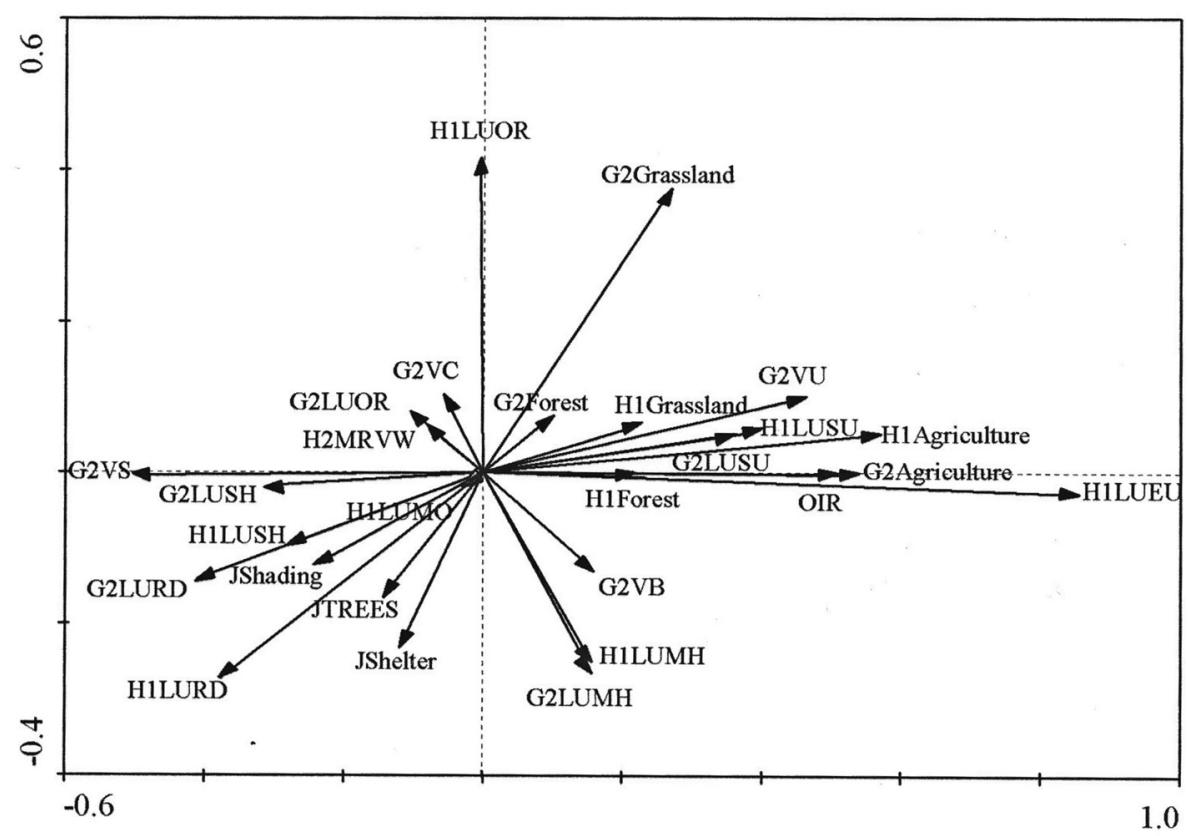

Figure 5. CCA analysis of RHS variables (grouped) of the river corridor and fish density. Only the environmental variables are represented. Análisis CCA de las variables RHS (agrupadas) del corredor fluvial y la densidad de peces. Se representan solamente las variables ambientales.

tioned environmental variables and the most disturbed stations are linked to the second group of variables related to disturbance.

CCA analysis of the fish assemblages (Fig. 5) was based on 64 sites (the ones where no fish were captured were excluded). Similar to the macroinvertebrate data there is a gradient along axis 1 with variables that indicate low human impacts (G2VS-complex vegetation in the banks) and rocky habitats (G2LURD and H1LURD) on the left hand side and variables associated with the influence of agriculture (H1Agriculture and G2Agriculture) and intensive eucalyptus plantations on the right hand side (H1LUEU).

The CCA analysis relating RHS with the macrophytes (Fig. 6) also separates the effects of perturbation (linked to the presence of grasslands (H1grass and G2grass) from lower changes on soil use (G2LURD, H1LURD, JShelter, and G2Forest). Other important aspects become apparent when the outputs from each analysis are compared (Table 3). The eigen values and correlations species-environment indicate that the explanation of data variance is highest between the
RHS variables and macrophyte communities and lowest for the macroinvertebrate assemblages.

Finally several CAs were calculated between the RHS indices (partial and total HQAs and HMS) and different sets of environmental descriptors, in order to test the dependence of the indices on the surrounding environmental conditions (Table 4). The data sets were : a) environment -comprising all the variables presented in Table 1; b) FAME variables; c) physicochemical water quality parameters $(n=16)$; d) typology; e) typology and soil use.

The expressed canonical $\mathrm{R}$ provides information on how redundant one set of variables is when it is compared to another set of variables. The high canonical $\mathrm{R}$ values (mostly $>0.7$ ) indicates that RHS indices are strongly dependent on the various sets of environmental data, in particular the global environmental data and the water quality data. Due the high redundancy verified between chemical variables it was not possible to know what part of the variance in each group of biological elements is explained by these parameters. 
Table 4. Results of CA between the different sets of environmental descriptors and the RHS indices (partial HQA indices and HMS). The proportion of the variance extracted, the redundancies shared by each matrix and index of total redundancies of each pair of matrices (canonical R) are shown. Resultados del CA entre los diferentes conjuntos de descriptores ambientales y los índices de RHS (HQA el índices parcial y HMS). Se indican la proporción de la variación extraída, la redundancia compartida por cada matriz. y el índice de redundancia total de cada par de matrices ( $R$ canónico).

\begin{tabular}{|c|c|c|c|c|c|}
\hline \multirow{2}{*}{ Matrices } & \multicolumn{2}{|c|}{ Extracted variance } & \multicolumn{2}{|c|}{ Redundance } & \multirow{2}{*}{ Canonical $\mathbf{R}$} \\
\hline & Environmental data & RHS indices & Environmental data & RHS indices & \\
\hline Environment X Indices & 48.00 & 100.00 & 29.00 & 63.85 & 0.938 \\
\hline FAME X Indices & 100.00 & 89.60 & 31.21 & 25.39 & 0.751 \\
\hline Water quality $\mathrm{X}$ Indices & 72.30 & 100.00 & 25.68 & 42.54 & 0.920 \\
\hline Tipology X Indices & 100.00 & 57.46 & 28.33 & 14.22 & 0.676 \\
\hline Tipology and soil use X Indices & 100.00 & 100.00 & 31.42 & 29.86 & 0.759 \\
\hline
\end{tabular}

\section{DISCUSSION}

The main purpose of RHS is to quantify the magnitude of global impacts acting on the stream habitats at a reach scale, with the explicit aim of providing river management bodies with information on sustaining and enhancing biodiversity. This study has illustrated several shortcomings in the RHS methodology that prevent the above objective from being attained. HQA and HMS indices were shown to be inefficient in assessing perturbation. Further multivariate analyses (MDA and CA) illustrated that that regional variables (land use, typological factors etc) exert an influence on RHS descriptors and derived indices (Tables 2 and 4). Therefore, special care is necessary when comparing the results of the RHS assessment procedure along the fluvial network of river systems since the data obtained reflects the natural variation of the physical habitat. The MDS ordinations (Figs. 1 and 2) also indicate that RHS descriptors of instream condition contribute little to habitat degradation assess-

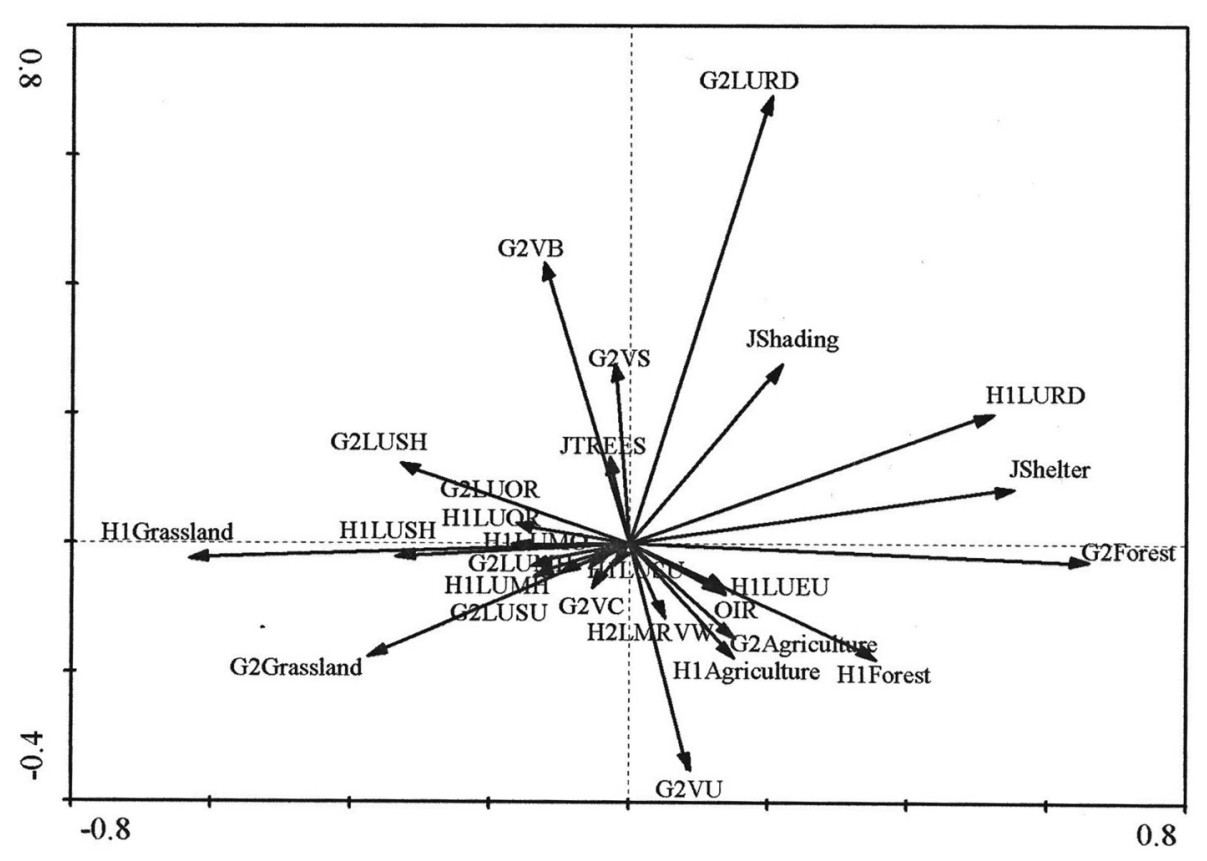

Figure 6. CCA analysis of RHS variables of the river corridor and the macrophytes. Only the environmental variables are represented. Análisis CCA de las variables RHS del corredor fluvial y los macrófitos. Unicamente se representan las variables ambientales. 
ment when compared to the RHS variables characterizing river corridor.

The attempt to link physical factors with biological condition is probably one of the most important challenges in establishing reliable habitat indices, a fact recognized by several authors (Armitage \& Pardo, 1995; Newson et al., 1998; Tickner et al., 2000). Using CCA, the biological responses analysed in this study (Figs. 4-6) clearly showed that each biotic assemblage (invertebrates, fish, and macrophytes) responded differently to the selected RHS river corridor variables; the macrophyte community showed the best relation with these RHS features and the benthic macroinvertebrate assemblages the weakest. Chessman et al. (2006) also linked distinct geomorphic units (medium to small scale morphological variables) to four aquatic communities (invertebrates, macrophytes, diatoms, and fishes) and found that each assemblage differed significantly between units, especially the two first communities.

In this study, a large part of the differences found to exist between the biological communities can be attributed to experimental design, namely the sampling strategies used for each type of assemblage. In the case of the macroinvertebrate community in particular, collections were dependent on small scale environmental parameters, whereas aquatic macrophytes were collected over a far larger area of the entire RHS unit. Parssons et al. (2004) stated that habitat assessment protocols should have the following properties: ability to predict physical features from natural to degraded sites, using the first ones for comparison, rapid data collection, the ability to be used by non-experts, and the inclusion of variables that describe geomorphological processes that are relevant to the biota.

However, the ability to assess disturbance is just as important as linking habitats with faunal composition. Do these findings show that variables related to river corridor best reflect the impact of human pressures? Low-scale characteristics appear to be more important to aquatic communities than those at higher spatial scales, especially concerning diversity (Tickner at al., 2000). However, differences in physical habitats across different river types have to be viewed as responses that take place within a hierarchical structure, with low-scale physical variables nested within and shaped by those occurring at higher scale influences (Frissell et al., 1986; Hawkins et al., 1993; Thompson et al., 2001); but these relations are mediated by riparian buffer types and their management (Nerbonne \& Vondracek, 2001). The effects of local and regional processes are complex, not only because they interact but also because they may linked to different forms of biological expression. For example fish communities in temporary Mediterranean streams (Mesquita et al., 2006) were shown to respond to both set of spatial scales, but landscape descriptors influenced species richness whereas local variables contributed to variation in abundance.

A handicap of RHS is that is based only on reach scale variables, with a lack of macro-scale (regional or basin) variables, a failing common to other habitat indices. When comparing three river habitat assessment methods including RHS, Raven et al. (2002) found that none of them provided clear links between local habitat features and geomorphological processes. As a result of such constraints Amoros (2001) developed a hierarchical framework for the design of process-orientated restoration projects with three nested levels (fluvial sectors, floodplain waterbodies, and mesohabitats). A similar approach was designed by Thompson et al. (2000), where the hierarchical steps considered necessary for a full assessment included basin type, landscape units, river style (reach type), geomorphic units, and hydraulic units. However, indices incorporating multiple spatial scales face the problem of weak relationships between larger scale descriptors and the biological components, when compared to local variables (Tickner et al., 2000; Oliveira \& Cortes, 2005). The scarce evidence for close links may be imputed to the role of riparian ecotones as buffers, mitigating the effect of disturbances produced at larger scales upon the local habitat by retaining sediments and nutrients and modifying energy source input (Naiman, 1992; Jaworski, 1993; Roth et al., 1996).

However, authors like Gergel et al. (2002) do not agree with the inclusion of large-scale 
abiotic variables in monitoring programmes because of increasing costs and reduced link of such factors with the biota. We must point out the need of further research on the identification and selection of appropriate landscape metrics as potential tools in predicting aquatic and riverine habitat quality.

The demands of the WFD, which establish monitoring and river management under the framework of the basin, cannot be overlooked. Broad-scale ecosystem modelling at the basin level, including landscape attributes and the identification of existing pressures could provide promising tools for developing sustainable river management policies (Harper et al., 1999; Raven et al., 2002), which should be incorporated into habitat system assessments such as RHS, since they may aid in linking processes and form over different scales (Newson, 2002). Landscape metrics that quantify the degree of patchiness or fragmentation should also be incorporated into the link between stream condition and landscape, since information on the proportion of the different types of land cover represent coarse information of soil use. However, successfully linking landscape to stream status using statistical approaches is only a part of the problem.

The indices describing the physical character of streams, like RHS, also do not generally include parameters of hydraulic geometry or geomorphic processes along the stream corridor, like stream power or the resistance to flow and velocity, which are related to sediment transport or corridor adjustments, often with dramatic implications on habitat use by the biota. Hydrodynamics play an important role in regulating biological functions (Stazner et al., 1988) and even simple hydraulic variables like the Froude or the Reynolds number can explain fish population structure (Lamouroux et al., 1999; Malavoi \& Souchon, 2002).

Other aspects that may improve fluvial corridor assessment should be considered particularly in Iberian streams which are characterised by extremely irregular flow patterns, For instance, disturbed sites are more susceptible to invasion by alien plant species (Aguiar et al., 2001). Assessment of invasibility patterns must include not only species presence or richness (such as in RHS) but also estimates of abundance such as foliar cover or biomass (Ferreira \& Aguiar, 2006). In the environmental quality assessment of riparian zones González del Tanago \& Garcia de Jalón (2006) include seven attributes related to the hydrological and ecological functioning of these systems namely longitudinal continuity, lateral dimensions of the floodplain, composition and structure of riparian vegetation, natural woody species regeneration, bank conditions, lateral connectivity, and permeability of riparian soils. However consideration must be given to including such a large number of variables, which may result in the assessment method becoming overly cumbersome.

Although assessment systems such as RHS are appropriate for high gradient streams, they are certainly less effective in non-wadeable rivers because of the difficulty in assessing and recording the listed physical features on both the banks and along transects with considerable length. Such criticism has led to the development of specific protocols for assessing physical habitat quality in non-wadeable river systems such as the NWHI (Wilhelm et al., 2005).

Caution must be exercised in making definitive conclusions about the relative importance of land practices, riparian management and habitat features in shaping the aquatic communities. In this study, we hypothesised that sampling strategy may have exerted a significant effect on the results obtained. Several other authors (Allan et al., 1997; Nerbonne \& Vondracek, 2001) have reported that study design (distribution of sampling stations along the watershed or concentrating on a few tributaries) could be also the responsible for the different findings and conclusions related to land-use studies. Hasty decisions concerning relationships according to Allan (2004) are caused by the lack of explicit consideration of the inherent mechanisms involved, a shortcoming that must be overcome through future research. Allan also states that for management purposes it is not sufficient to diagnose when a system is impaired, but there is also a need for mechanistic understanding, 
namely the dependence of biota on physical habitat, water quality or food web disturbances.
Thus, additional work needs to be done to discriminate RHS variables from the influence

Appendix 1. Transformation of the original RHS variables by their aggregation according to their affinity. The adapted variables were used in the data treatment. Transformación de las variables RHS originales por su agregación atendiendo a su afinidad. Las variables adaptadas se usaron en el tratamiento de los datos.

Number of riffles, pools, side and point bars (A)
ENR - No. Riffles; ENP - No. Pools; EPSB - $\sum$ of variables:
Number of unvegetated point bars, number of vegetated point
bars, number of unvegetated side bars, number of vegetated side
bars.

\section{Artificial features (A)}

FAF - $\sum$ of variables: Weirs/sluices, culverts, bridges, outfalls/ intakes, fords, deflectors/groyns/croys.

\section{Physical attributes (A)}

Bank material (dominant - G1BMD, mean - G1BMM, and standard deviation - G1BMSD); artificial bank material - G1BMAS $-\sum$ of variables: concrete, sheet piling, wood piling, gabion, brick/laid stone, rip-rap, tipped debris, fabric, bio-engineering materials; G1BM - $\sum$ of variables: Resectioned (reprofiled), reinforced, Poached (bare), Artificial berm, embanked; Channel substrate (dominant - G1CSD, mean - G1CSM, and standard deviation - G1CSSD); G1FT - $\sum$ of variables: Free fall, chute, broken standing waves (white water), unbroken standing waves, chaotic flow, rippled, upwelling, smooth, no perceptible flow, dry (no flow); G1CM - $\sum$ of variables: Resectioned, reinforced, culverted, dam/weir/sluice, ford (man-made); G1GE - $\sum$ of variables: Exposed bedrock, exposed boulders, vegetated rock; Channel features: Number of sub-channels for braided rivers G1CFBR.

\section{Banktop land-use and vegetation structure (B)}

G2Forest - $\sum$ of variables: Broadleaf/mixed woodland (seminatural), Broadleaf/mixed plantation, Coniferous woodland (semi-natural), Coniferous plantation; G2LUSH - Scrub and shrubs; G2LUOR - Orchard; G2LUMH - Moorland/heath; G2Grassland - $\sum$ of variables: Rough unimproved grassland/pasture, inproved/semi-improved grassland, all herb/rank vegetation; G2LURD - Rock, scree or/and dunes; G2LUSU - Suburban/Urban development; G2Agriculture - $\sum$ of variables: Tilled land, irrigated land, parkland or gardens; G2VB $\sum$ of variables: Banktop and bankface bare vegetation structure; G2VU - $\sum$ of variables: Banktop and bankface uniform vegetation structure; G2VS - $\sum$ of variables: Banktop and bankface simple vegetation structure; G2VC - $\sum$ of variables: Banktop and bankface complex vegetation structure.

\section{Channel vegetation types (A)}

G3Emerg - Emergent reeds; sedges; rushes; grasses and horsetails; G3 Hyd - $\sum$ of variables: Liverworts/Mosses/Lichens, Emergent broad-leaved Herbs, Free-floating, amphibious submerged broad-leaved, Submerged linear-leaved, Submerged fineleaved; G3Alg - Filamentous algae.

\section{Land-use within $50 \mathrm{~m}$ of banktop (B)}

H1Forest - $\sum$ of variables: Broadleaf/mixed woodland (seminatural), broadleaf/mixed plantation, coniferous woodland (semi-natural), coniferous plantation; H1LUSH - Scrub and shrubs; H1LUOR - Orchard; H1LUMH - Moorland/heath; H1LUEU - Eucaliptus stand; H1LUMO - Mediterranean oak forest; H1Grassland - $\sum$ of variables: Rough unimproved grassland/pasture, Inproved/semi-improved grassland, tall herb/rank vegetation; H1LURD - Rock, scree or and dunes; H1LUSU Suburban/urban development; H1Agriculture - $\sum$ of variables: Tilled land, irrigated land; parkland or gardens.

\section{Galeria ripícola (B)}

H2MRVW - Mean riparian vegetation width.

\section{Bank profiles (A)}

IBPVS - $\sum$ of variables: Vertical/undercut, vertical with toe, steep $\left(>45^{\circ}\right)$; IBPG - Bank profiles gentle; IABF - $\sum$ of variables: Resectioned (reprofiled), reinforced-whole, reinforced-top only, reinforced-toe only, artificial two-stag, poached bank, embanked, set-back embankment.

\section{Extent of trees and associated features (B)}

JTREES - Trees; JShading - $\sum$ of variables: Shading of channel, overhanging boughs; JShelter $-\sum$ of variables: Exposed bankside roots, underwater tree roots, fallen trees, large woody debris.

\section{Extent of channel and bank features (A)}

KEFT - $\sum$ of variables: Free fall flow, chute flow, broken standing waves, unbroken standing waves, rippled flow, upwelling, smooth flow, no perceptible flow, dry, marginal dead water; KEC - Eroding cliff; KEGE - $\sum$ of variables: Exposed bedrock, exposed boulders, vegetated bedrock/boulders; KMCB - $\sum$ of variables: Unvegetated mid-channel bars, unvegetated mid-channel bars; KMI - Mature Island.

\section{Features of special interest (A)}

MMC - $\sum$ of variables: Braided channel, side channel(s); MWC $-\sum$ of variables: Nat. waterfall(s) $>5 \mathrm{~m}$ high, nat. waterfall(s) $<$ $5 \mathrm{~m}$ high, nat. cascade(s); MB - $\sum$ of variables: Very large boulders ( $>1 \mathrm{~m})$, Floodplain boulder deposits; MD - $\sum$ of variables: Debris dam(s), leafy debris.

\section{Channel dimensions (A)}

LLP - The ratio between the variables water width $(\mathrm{m})$ and water depth (m); LBH - Mean banktops hights of both banks; LCBW - Bankfull width.

Notable nuisance plant species (B)

OIR - $\sum$ of variables: Acácia; Ailanthus altissima; Arundo donax. 
of organic pollution in order to proceed to the mentioned diagnosis of the impairment causes.

This work was aimed at making a significant contribution to overcoming the paucity of tested assumptions on the relationship between channel morphology, aquatic habitat and the biota in RHS, making way for further developments of this method by creating habitat-species association based scoring systems. We believe that it has also highlighted the need for future research in order to produce habitat evaluation systems and indices that have biological relevance, which must accommodate appropriate sampling protocols and a wide range of physical features covering multiple spatial levels.

\section{BIBLIOGRAPHY}

AGUIAR, F. C., M. T. FERREIRA, \& I. MOREIRA. 2001. Exotic and native vegetation establishment following channelazation of a Western Iberian River. Regulated Rivers: Research \& Management, 17: 509-526.

ALLAN, J. D. 2004. Influence of land use and landscape setting on the ecological status of rivers. Limnetica, 23: 187-198.

ALLAN, J. D., D. L. ERICKSON, \& J. FAY. 1997. The influence of catchment land use on stream integrity across multiple spatial scales. Freshwat. Biol., 37: 149-161.

AMOROS, C. 2001. The concept of habitat diversity between and within ecosystems applied to river side-arm restoration. Environmental Management, 28: 805-817.

ARMITAGE, P. D. \& I. PARDO. 1995. Impact assessment of regulation at the reach level using macroinvertebrate information from mesohabitats. Regulated Rivers: Research \& Management, 10: 147-158.

BINDER, W. und W. KRAIER. 1999. Gewässerstrukturgütekartierung Bundesrepublik DeutschlandStand und Ausblick. Wasserwirtschaft, 89: 30-33.

BOON, P. J., N. T. H. HOLMES, P. S. MAITLAND \& I. R. FOZZARD. 1997. A system for evaluating rivers for conservation (SERCON): development, structure and function. In: Freshwater quality: defining the indefinable? P. J. Boon \& D. L. Howell (eds.): 299-326. The Stationery Office, Edinburgh.
BRIERLEY, G. J. \& K. FRYRS. 2000. River styles: a geomorphic approach to catchment characterisation: implcations for river rehabilitation in Bega catchment, New South Wales, Australia. Environmental Management, 25: 661-679.

BUFFAGNI, A., S. ERBA, M. CAZZOLA \& J. L. KEMP. 2004. The Aqem multimetric system for the southern Italian Apennines: assessing the impact of water quality and habitat degradation on pool macroinvertebrates in Mediterranean rivers. Hydrobiologia, 516: 313-329.

CHESSMAN, B. C., K. A. FRYIRS, \& G. J. BRIERLEY. 2006. Linking geomorphic character, behaviour and condition to fluvial biodiversity: implications for river management. Aquatic Conservation: Marine and Freshwater Ecosystems., 16: 267-288.

CLARKE, K. R. \& R. M. WARWICK. 1999. The taxonomic distinctness measures of biodiversity: weighting of steps lengths between hierarchical levels. Mar. Ecol. Prog. Seas., 184: 21-29.

DAVENPORT, J., GURNELL, A. M. \& P. D. ARMITAGE. 2004. Habitat survey and classification of urban rivers. River Research and Applications, 20: 687-704.

FERREIRA, M. T. \& F. C. AGUIAR. 2006. Riparian and aquatic vegetation in Mediterranean-type Strems (Western Iberia). Limnetica, 25: 411-424.

FRISSEL, C. A., W. J. LISS, C. E. WARREN \& M. D. HURLEY. 1986. A hierarchical framework for stream habitat classification. Environmental Management, 10: 199-214.

FRYIRS, K. 2003. Guiding principles for assessing geomorphic river condition: application of a framework in the Bega Catchment, South Coast, New South Wales, Australia. Catena, 53: 17-52.

GERGEL S. E., M. G. TURNER, J. R. MILLER, J. M. MELACK \& E. H. STANLEY. 2002. Landscape indicators of human impacts to riverine systems. Aquat. Sci., 64: 118-128.

HARPER, D. M., M. EBRAHIMNEZHAD, E. TAYLOR, S. DICKINSON, O. DECAMP, G. VERNIERS \& T. BALBI. 1999. A catchment-scale approach to the physical restoration of lowland U.K. rivers. Aquatic Conservation: Marine and Freshwater Ecosystems, 9: 141-157.

HAWKINS, C. P., J. L. KERSHNER, P. A. BISSON, M. D. BRYANT, L. M. DECKER, S. V. GREGORY, D. A. McCULLOUGH, C. K. OVERTON, G. H. REEEVES, R. J. STEEDMAN \& M. K. 
YOUNG. 1993. A hierarchical approach to classifying stream habitat features. Fisheries, 18(6): 310.

KAMP, U., R. BOCK, \& K. HOLZL. 2004. Assessment of river habitat in Brandenburg Germany. Limnologica, 34: 176-186.

GONZÁLEZ DEL TANAGO, M. \& D. GARCÍA DE JALÓN. 2006. Attributes for assessing the environmental quality of riparian zones. Limnetica, 25 : 389-402.

JAWORSKI, A. 1993. The application of the ecotone concept in defining nutrient management requirements for the upper Potomac River basin. Hydrobiologia, 251: 341-349.

JONGMAN, R. H. G., C. J. F. Ter BRAAK \& O. F. R. Van TONGEREN. 1989. Data Analysis in Landscape Ecology. Pudoc, Wageningen, The Netherlands. 299 pp.

LADSON, A. R., L. J. WHITE, J. A. DOOLAN, B. L. FINLAYSONS, B. T. HART, P. S. LAKE \& J. W. TILLEARD. 1998. Development and testing of an index of stream condition for waterway management in Australia. Freshwat. Biol., 41: 453468.

LAMOUROUX, L. B., J. M. OLIVIR, H. PERSAT, M. POUILLY, Y. SOUCHON, \& B. STATZER. 1999. Predicting community characteristics from habitat conditions: fluvial fish and hydraulics. Freshwat. Biol., 42: 275-299.

LOGAN, P. \& M. FURSE. 2002. Preparing for the European Water Framework Directive-making the links between habitat and aquatic biota. Aquatic Conservation: Marine and Freshwater Ecosystems, 12: 425-437.

MADDOCK, I. 1999. The importance of river habitat assessment for evaluating river health. Freshwat. Biol., 39: 325-337.

MALAVOI, J. R. et Y. SOUCHON. 2002. Description standardisée des principaux faciés d'écoulement observables en riviére: clé de détermination qualitative et mesures physiques. Bull. Fr. Pêche Pisc., 365/367: 357-372.

MESQUITA, N., M. M. COELHO \& F. MAGALHÃES. 2006. Spatial variation in fish assemblages across small Mediterranean drainages: effects of habitat and landscape context. Environ. Biol. Fish, 77: 105-120.

MUHAR, S., M. SCHWARZ, S. SCHMUTZ \& M. JUNGWIRTH. 2000. Identification of rivers with good habitat quality: methodological approach and applications in Austria. Hydrobiologia, 422/423: 343-358.

MUHAR, S., G. UNFER, S. SCHMUTZ, M. JUNGWIRTH, G. EGGER, \& K. ANGERMANN. 2004. Assessing river restoration programmes: habitat conditions, fish fauna and vegetation as indicators for the possibilities and constraints of river restoration. In: Proceedings of the Fifth International Conference on Ecohydraulics-Aquatic Habitats: Analysis and Restoration. D. Garcia de Jalon \& P. V. Martínez (eds.): 300-305. Madrid.

NAIMAN, R. J. 1992. Watershed management: balancing sustainability and environmental change. Springer-Verlag, New York. 542 pp.

NERBONNE, B. A. \& VONDRACEK. 2001. Effects of local land use on physical habitat, benthic macroinvertebrates and fish in the Whitewater River, Minnesota, USA. Environmental Management, 28: 87-89.

NEWSON, M. D. 2002. Geomorphological concepts and tools for sustainable rivers ecosystem management". Aquatic Conservation: Marine and Freshwater Ecosystems, 12: 365-379.

NEWSON, M. D., D. M. HARPER, C. L. PADMORE, J. L. KEMP \& B. VOGEL. 1998. A cost effective approach for linking habitats, flow types and species requirements. Aquatic Conservation: Marine and Freshwater Ecosystems, 8: 431-446.

NRA-National Rivers Authority. 1992. River corridor surveys, method and procedures. National Rivers Authority, Conservation Technical Handbook No. 1, NRA Bristol. 106 pp.

NRA-National Rivers Authority. 1996. River habitats in England and Wales: a national overview. River Habitat Survey. Report no. 1. National Rivers Authority, Bristol, $53 \mathrm{pp}$.

OLIVEIRA, S. V. \& R. M. V. CORTES. 2005. A biologically relevant Habitat Condition Index for streams in Northern Portugal. Aquatic Conservation: Marine and Freshwater Ecosystems, 15: 189210.

PARSONS, M., M. C. THOMS \& R. H. NORRIS. 2004. Development of a standardised approach to river habitat assessment in Australia. Environmental Monitoring and Assessment, 98: 109-130.

RAVEN, P. J., P. FOX, M. EVERARD, N. T. H. HOLMES \& F. H. DAWSON. 1997. River Habitat Survey: a new system for classifying rivers according to their habitat quality. In: Freshwater Quality: Defining the Indefinable? P. J. Boon \& D. L. Howell (eds.): 215-234. Stationery Office, Edinburgh. 
ROTH, N. E., J. D. ALLAN \& D. L. ERICKSON. 1996. Landscape influences on stream biotic integrity assessed at multiple spatial scales. Landscape Ecology, 11: 141-156.

SCHMUTZ, S. 2004. Development, evaluation \& implementation of a standardised fish-based assessment method for the ecological status of European rivers: a contribution to the Water Framework Directive (FAME). Scientific achievements, Sections $5 \& 6$ (Final Report). Institute for Hydrobiology and Aquatic Ecosystem Management University of Natural Resources and Applied Life Sciences, Vienna. FAME, $41 \mathrm{pp}$.

STALKNER, C. B. 1994. Evolution of instream flow habitat modelling. In: The Rivers Handbook. P. Calow \& G. E. Petts (eds.): 276-286. Oxford, Blackwell Scientific Publications.

STATSOFT INC. 2004. Statistica (Data Analysis Software System). Version 7, www. Statsoft.com, Tulsa, USA.

STATZNER, B., J. A. GORE \& V. H. RESH. 1988. Hydaulic stream ecology: observed patterns and potential applications. J. North Am. Benthol. Soc., 7: 307-360.
Ter BRAK, C. J. F. \& P. SMILAUER. 2002. Canoco for Windows version 4.5. Biometris, Plant Research International, Wageningen (Netherlands).

THOMPSON, J. R., M. P. TAYLOR, K. A. FRYIRS \& G. J. BRIERLEY. 2001. A geomorphological framework for river characterization and habitat assessment. Aquatic Conservation: Marine and Freshwater Ecosystems, 11: 373-389.

TICKNER, D., P. D. ARMITAGE, M.A. BICKERTON \& K. A. HALL. 2000. Assessing stream quality using information on mesohabitat distribution and character. Aquatic Conservation: Marine and Freshwater Ecosystems, 10: 179-186.

WILHELM. J. G. O., J. D. ALLAN, N. J. WESSELL, R. W. MERRIT \& K. W. CUMMINS. 2005. Habitat assessment of non-wadeable rivers in Michigan. Environmental Management, 4: 592609.

WRIGHT, J. F. 2000. An introduction to RIVPACS. In: Assessing the biological quality of fresh waters: RIVPACS and other techniques. J. F. Wright, D. W. Sutcliffe \& M. T. Furse (eds.): 1-23. Freshwater Biological Association, Ambleside, Cumbria, U.K. 
